ERJ

Engineering Research Journal

Faculty of Engineering

Minoufiya University

\title{
TENSILE AND SHEAR PROPERTIES OF CROSS-PLY COMPOSITE LAMINATES WITH DIFFERENT OFF-AXIS ANGLES
}

\author{
A.I. Selmy, U.A. Khashaba, I.A. El-Sonbaty, M.A. Abd El-Baky \\ Mechanical Design and Production Engineering Department, Faculty of Engineering, \\ Zagazig University, P.O. Box 44519, Zagazig, Egypt.
}

\begin{abstract}
A double-notch and modified Iosipescu shear test fixtures have been designed and manufactured to investigate in-plane shear properties of cross-ply composite laminate with different off-axis angles. A cross-ply $\left[0^{\circ} / 90^{\circ}\right]_{2 s}$ glass/polyester composite laminate was manufactured using hand lay-up technique. This laminate was cut at different off-axis angles $\left(\theta^{\circ}=0^{\circ}, 15^{\circ}, 30^{\circ}\right.$ and $\left.45^{\circ}\right)$ to give different stacking sequences $\left(\left[0^{\circ} / 90^{\circ}\right]_{2 s}, \quad\left[15^{\circ} /-75^{\circ}\right]_{2 s}, \quad\left[30^{\circ} \%-60^{\circ}\right]_{2 s}\right.$ and $\left[45^{\circ} /-45^{\circ}\right]_{2 s}$ respectively). The tensile properties (strength, modulus, and Poisson's ratio) were determined experimentally and theoretically from the elastic properties of the constituent materials. Shear properties (strength and modulus) were determined experimentally by the two tests. Shear modulus were predicted theoretically from the elastic properties of the constituent materials.

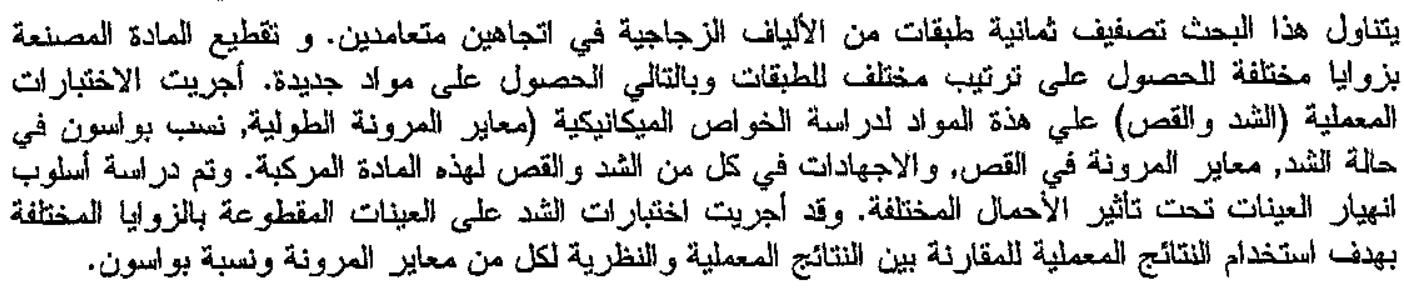

Keywords: composite, Iosipescu, double-notch shear test, cross-ply, off-axis angle, elastic properties, shear properties, tension test.

\section{INTRODUCTION}

During the last decades, an intensive research effort. has been devoted to the experimental characterization of composite laminate shear behavior. Different shear test methods have been proposed for measuring inplane shear properties (strength and stiffness). Inplane shear behavior could be determined by Iosipescu test [1-4], off-axis tension test [5], rail shear test [6], torsion test [7], and double notch shear test [8].

Compared with other test methods, Iosipescu shear test was known as one of the most efficient methods. It uses a flat specimen which is easier to be manufactured, achieves a uniform shear stress state over the test region, and more reliable results can be obtained. On other hand, this test requires larger specimen, and it is not suitable for elevated temperature testing with its commercial metallic fixture.

The double-notch shear test, where notches make the shear stress distribution in specimen highly nonuniform [8], was used in this study. Since it is inexpensive, the ASTM standardized it for plastic and ceramic matrix composites. The research community uses it frequently for comparative studies and quality checks [8]. The double-notch shear test method covers the determination of in-plane shear strength of reinforced plastics in flat sheet form in thickness ranging from 2.54 to $6.6 \mathrm{~mm}$ [9].

In this study, tensile and in-plane shear properties of cross-ply glass/polyester laminate with different offaxis angles will be examined experimentally and theoretically. In-plane shear properties will be determined using two tests, Iosipescu shear test fixture designed and manufactured according to Wyoming specifications (ASTM D5379-93) [10], and double notch shear test fixture manufactured according to ASTM D3846-02 [9]. All tests were carried out on a universal testing machine (testometric $200 \mathrm{kN}$ ). The cross-head speed of its loading member was $2 \mathrm{~mm} / \mathrm{min}$. The load deflection curves were obtained from the computer unit of the testing machine.

\section{EXPERIMENTAL WORK}

\subsection{Material and Specimen Preparation}

A . cross-ply glass/polyester laminate was manufactured using hand lay-up technique. The constituent materials and their elastic properties are illustrated in Table 1,2. 
Table 1. The constituent materials of GFRP composite laminates

\begin{tabular}{|l|l|}
\hline Materials & \multicolumn{1}{|c|}{ Type } \\
\hline Matrix & Polyester resin (SIROPOL 8230) \\
Catalyst & $\begin{array}{l}\text { Cobalt naphthanace }(0.5 \% \text { of matrix } \\
\text { volume) }\end{array}$ \\
Hardener & $\begin{array}{l}\text { Methyl Ethyl Ketone Peroxide }(0.6 \% \text { of } \\
\text { matrix volume }) \\
\text { E-glass (Roving) } \rho_{L}=2200 \mathrm{~g} / \mathrm{km}\end{array}$ \\
\hline
\end{tabular}

Table 2. The properties of E-glass fiber and polyester resin

\begin{tabular}{|c|c|c|c|}
\hline Constituent & \multicolumn{3}{|c|}{ Elastic properties } \\
\cline { 2 - 4 } materials & $E(\mathbf{G P a})$ & $\boldsymbol{G}(\mathbf{G P a})$ & $\boldsymbol{V}$ \\
\hline Polyester resin & 2.46 & 1.28 & 0.37 \\
E-Roving glass & 76 & 30.4 & 0.25 \\
\hline
\end{tabular}

A total of 8 templates were used to lay the fiber bundles in $0^{\circ}$ and $90^{\circ}$ directions. The parallel bundles of fiber glass were fixed on the frame of the templates using small pins. The normal distance between each adjacent parallel bundles was $5 \mathrm{~mm}$. The upper and Iower surfaces of the mould were glass plates treated by wax. . At first a thin layer of polyester resin was spread over the lower glass plate. The first template with $0^{\circ}$ oriented fibers was placed on the resin. Rolling the fibers impregnates them, squeezes any excess resin, displaces the air outwards. When the ply was fully impregnated, the bundles were loosen from the termplate. An amount of polyester resin followed by a template with $90^{\circ}$ oriented fibers was placed and so on until the whole laminate is constructed. The last layer was resin covered by a sheet of aluminum foil. The second glass plate was placed upon the laminate and a $25 \mathrm{~kg}$ weight was distributed over the glass plate. After 24 $h$, the glass plates and aluminum foil were removed and the laminate was completely cured at room temperature for 21 days giving a laminate with thickness varying from $6-6.4 \mathrm{~mm}$.

The plate was taken to the workshop and specimens were cut to the required dimensions using sawing and milling machines. The fiber volume fraction was determined experimentally using the ignition test according to BS 3691 [11]. The average value of fiber volume fraction was $42.59 \%$.

\subsection{Tension Test}

The test specimens were cut into strips with $250 \mathrm{~mm}$ length and $25 \mathrm{~mm}$ width Fig. 1. Four rectangular aluminum tabs were bonded to the gripping length $(60 \mathrm{~mm})$ of each test specimen using polyester resin. These end tabs reduce stress concentration from the grips, prevent the specimen slippage, transfer the compressive load from the testing machine to the specimen and prevent the specimen crushing between the grips. Two perpendicular strain gages were bonded on center region of the specimen to measure actual Young's modulus, major Poisson's ratio. Using the strain gauges gives actual strains compared with apparent strains that obtained from loaddisplacement diagram of the testing $\mathrm{m} / \mathrm{c}$. Three specimens (one with strain gauges and two without strain gauges) were tested for each off-axis angle. The strain were measured using Digital Strain Meter Tc-2lk model 232.

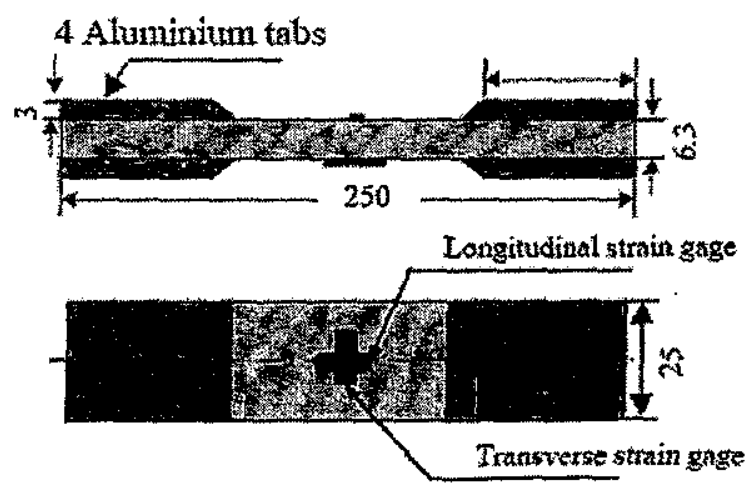

Fig. 1 Dimensions of tensile test specimen DIMS in (mm).

\subsection{Iosipescu Shear Test}

In-plane shear properties $\left(\tau_{x y}, G_{x y}\right)$ of cross-ply glass/polyester laminate with different off-axis angles were determined using modified Wyoming Iosipescu test fixture ,Fig.2, according to ASTM D5379-93 [10]. The left half of the fixture is fixed rigidly to the base plate along with spacer block which has a guide way to prevent the twisting of the movable (right) half. The entire front face of the specimen remains visible during testing and the progress of failure can be monitored visually.

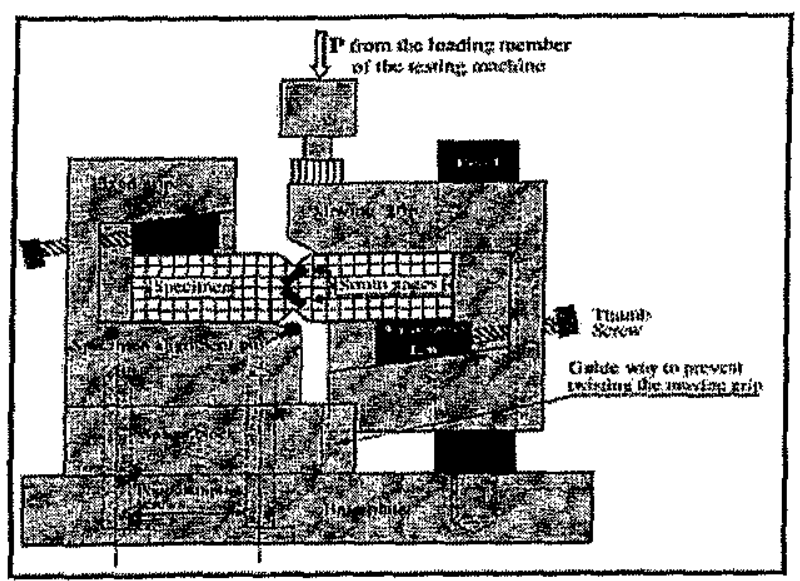

Fig 2 Iosipescu shear test.

The principle of the test is to apply a set of prescribed displacements on the V-notch specimen, so that the central region of the sample is under a state of predominant shear. These displacements are achieved through relative movement of the movable grip with respect to the fixed grip. Three specimens (one with 
strain gauges and two without strain gauges) were tested for each offaxis angle. The strain were measured using Digital Strain Meter Tc-21k model 232 .

\subsubsection{Preparation of Iosipescu shear specimens}

The test specimens were cut into strips with $76 \times 19.5$ $\mathrm{mm}^{2}$ using a rotating saw with narrow pitch to prevent the damage during cutting process. The width of the specimen was machined up to $19 \pm 0.05 \mathrm{~mm}$ using a milling machine. The final dimensions in $(\mathrm{mm})$ are illustrated in Fig. 3. $90^{\circ}$ double V-notches were machined mid-length through the thickness of the specimen using form-milling cutter for a depth of $3.8 \mathrm{~mm}$, which is about $20 \%$ of the specimen width. The radius of the notch root is $0.157 \mathrm{~mm}$ in all the specimens. To measure the shear strain $\left(\gamma_{x y}\right)$ and shear modulus $\left(G_{x y}\right)$ two strain gages were bonded at $+45^{\circ}$ and $-45^{\circ}$ at the center of the test specimen.

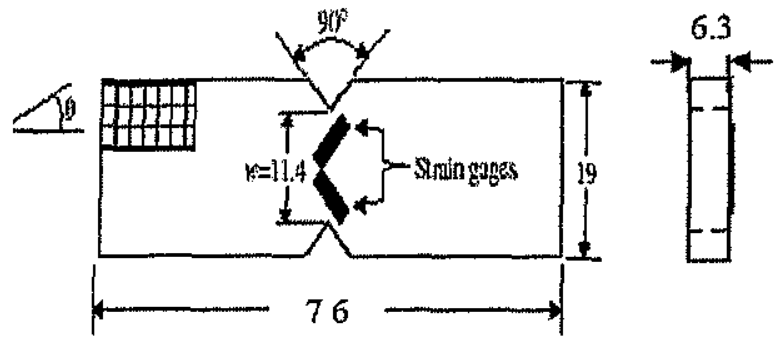

Fig. 3 Dimensions of Iosipescu specimens DIMS in (mm).

\subsubsection{The main features of this test are:}

1- Pure shear stress state at the specimen mid-length by applying two counter-acting moments.

2- a state of constant shear force through the middle section of the test specimen.

\subsection{Double Notch Shear (DNS) Test}

A series of Double Notch Shear (DNS) tests were conducted to examine the effect of shear length (S) on the in-plane shear strength of cross-ply glass/polyester laminates with different $\theta^{\circ}$. The in plane shear strength is measured by applying a compressive load to notch specimens of uniform width. Three specimens were tested for each $\theta^{\circ}$. The specimens are loaded in a supporting fixture Fig. 4.

\subsubsection{Preparation of double-notch shear (DNS) specimens}

The DNS test used is defined by ASTM D3846-02 [9]. The test specimens were cut into strips with $79.5 \times 13.5 \mathrm{~mm} 2$. The width of specimen was machined to $12.7 \pm 0.05 \mathrm{~mm}$. two centrally located notches machined halfway through the specimen thickness and spaced a (S) distance apart on opposing faces, Fig. 5.

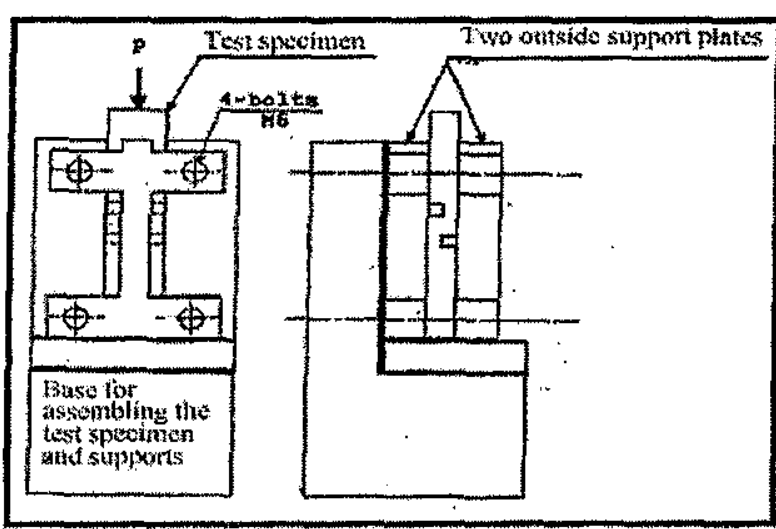

Fig. 4. Double-notch shear test supporting jig.

Quality of the notche cutting has a significant effect on the test results. Undercutting (where the notch doesn't reach the specimen midplane) leads to an increase in the measured strength. Over cutting (beyond the midplane of the specimen) leads to a decrease in the measured strength. The spacing between the two grooves varies from $S=4,7,10$ $\mathrm{mm}$. Failure of the specimens occurs in shear area between the two notches.

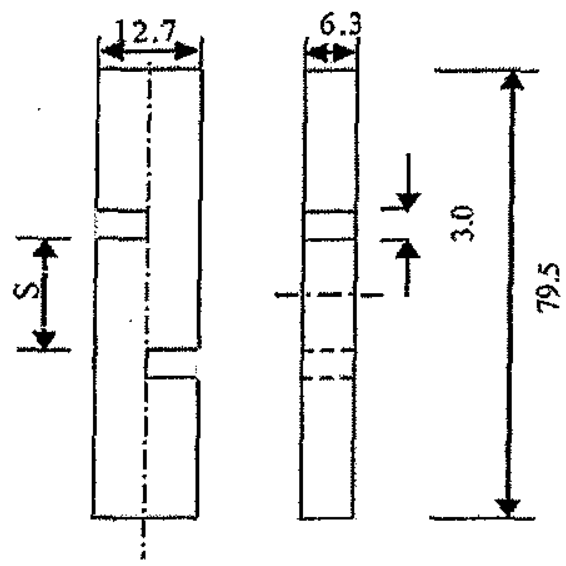

Fig. 5 In-plane shear specimen used in DNS test DIMS in (mm).

\section{RESULTS AND DISCUSSION}

\subsection{Tensile Properties of $\left[0^{\circ} / 90^{\circ}\right] 2 \mathrm{~s}$ Cross-ply Laminate With Different Off-axis Angles}

Fig. 6 shows stress-strain diagram of cross-ply glass/polyester specimens with $\left(0^{\circ}, 15^{\circ}, 30^{\circ}, 45^{\circ}\right)$ offaxis angles tested in tension.

The average values of ultimate tensile strengths were calculated from these curves and illustrated in Table 3. The main characteristic of these curves is the knee The reason of the knee is that, fiber and matrix carry the load until the strain reaches ultimate matrix strain 
at this moment matrix micro cracking begins. After that, the load redistribution occurs and load is transferred progressively to the fiber until the final fracture occurs. Redistribution of stress between fibers and matrix leads to another increasing in the tensile stresses with apparent tensile modulus lower than that for the initial linear portion. The final failure is catastrophic without any yielding. The reason of knee may be also due to slipping of test specimens. These curves are slightly non linear. The apparent tensile modulus of elasticity were calculated from slope of initial linear portion of stress-strain diagram.

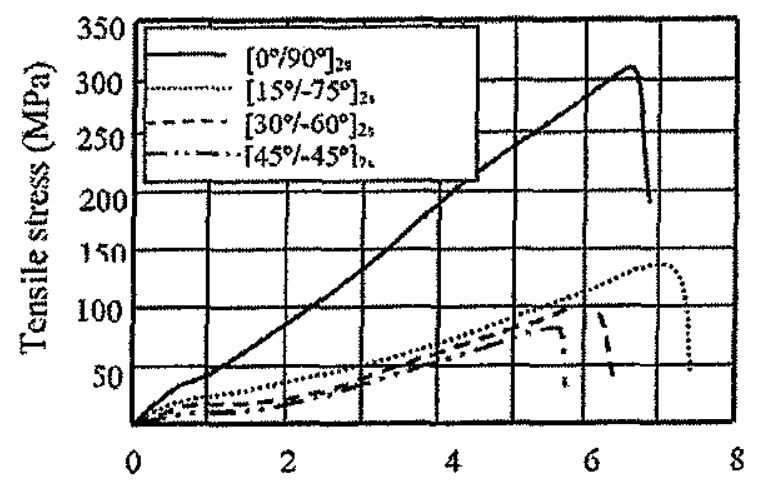

Fig. 6 Stress-strain diagram of cross-ply specimens with different off-axis angles.

Table 3: The mechanical properties of cross-ply composite laminate with different off-axis angles

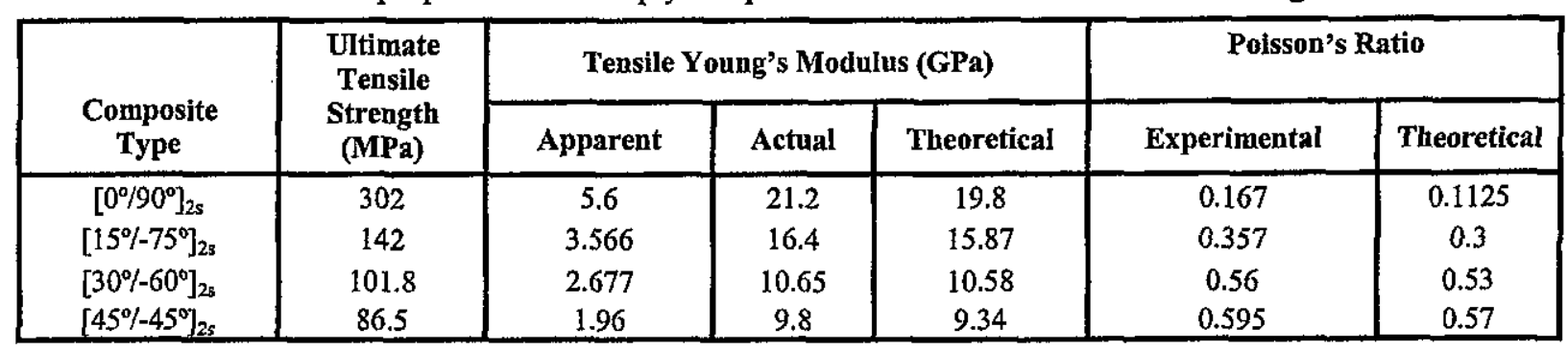

\subsubsection{Stress-streain diagrams from the strain gage readings}

Fig. 7 shows the longitudinal and transverse stressstrain diagrams of cross-ply GFRP composite specimens with different $\theta^{\circ}$. The strain values in these figures were obtained from the strain gauges. The actual Young's moduli were calculated at $0.5 \%$ longitudinal strain [4]. Table 3 shows a comparison between the apparent (from Fig. 6), theoretical, and actual Young's moduli (from Fig. 7).

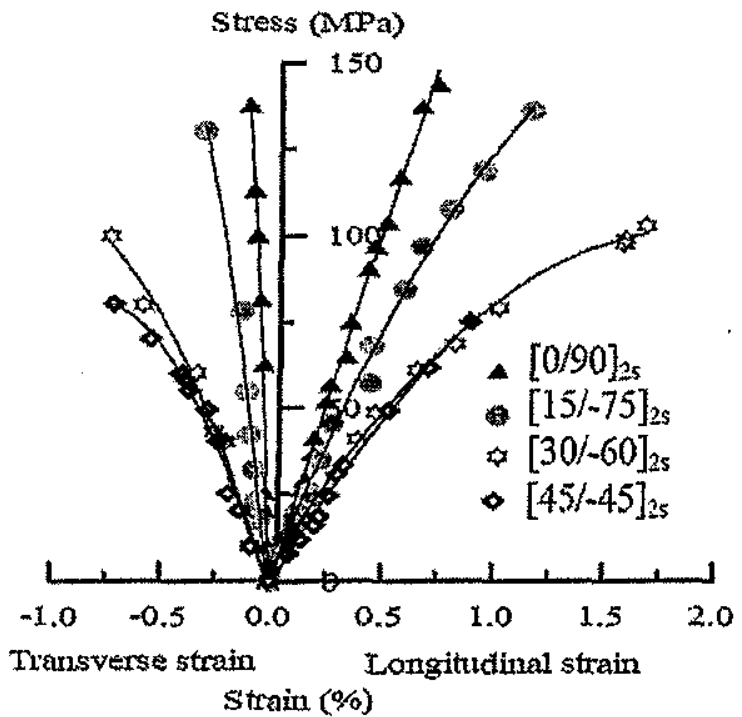

Fig. 7 Stress-strain relationship of cross-ply GFRP laminate with different off-axis angles.
The results indicate that the actual Young's moduli are about four orders of magnitude higher than the apparent Young's moduli. This was due to the displacement resulting from the clearance in the different joint in the testing machine, the specimen micro-slip, and shear deformation in the adhesive material (bonding matrix between specimen and aluminum tabs). These displacements were added to the specimen displacement resulting in low apparent Young's modulus [4].

Figure 8 shows the effect of off-axis angle on the actual, apparent, and theoretical values of Young's modulus of GFRP composite.

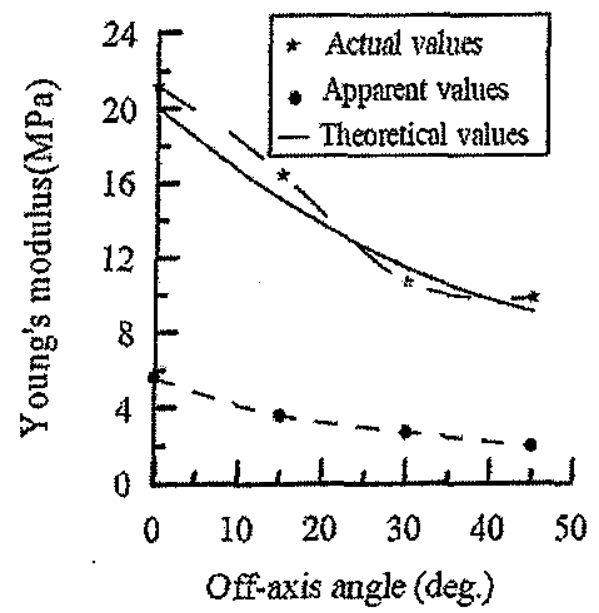

Fig.8 Relationship between off-axis angles, Young's moduli of GFRP laminate. 
It is obvious that, actual, apparent, and theoretical values of Young's modulus decrease as the off-axis angle increases. The actual values of young's modulus agree with the theoretical values.

\subsubsection{Major Poisson's ratio $\left(v_{x y}\right)$}

Table. 3 shows a comparison between theoretical and experimental values of Poisson's ratios for cross-ply laminate with $\left(0^{\circ}, 15^{\circ}, 30^{\circ}, 45^{\circ}\right)$ off-axis angles. Figure. 9 shows the effect of off-axis angle on the experimental and theoretical values of Poisson's ratio.

The major Poisson's ratio can be calculated from the following Eq. (1)

$$
v_{x y}=-\frac{-\varepsilon_{y}}{\varepsilon_{x}}
$$

It is obvious from Fig. 9 that Poisson's ratio values increases as off-axis angle increases the predicted values agree with the experimental results.

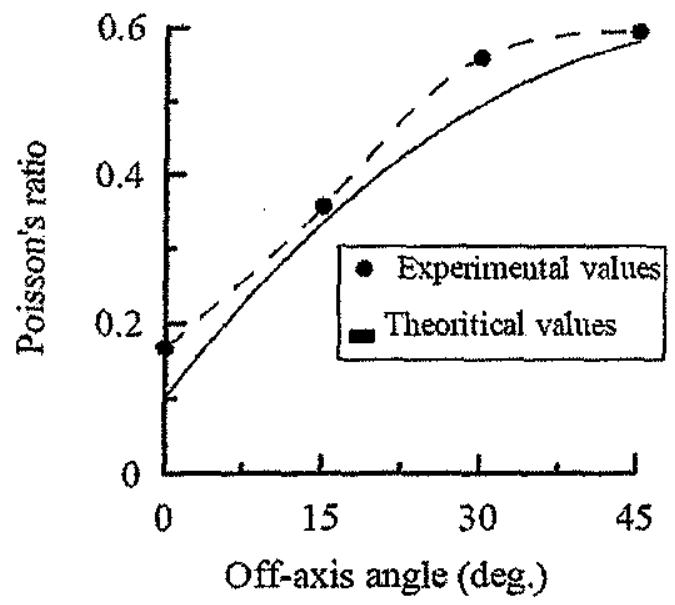

Fig. 9 Relationship between Poisson's ratio and offaxis angles of GFRP laminate.

\subsubsection{Failure modes of $\left[0^{\circ} / 90^{\circ}\right] 2 \mathrm{~s}$ laminate with different off-axis angles}

Failure occurred in $\left[0^{\circ} / 90^{\circ}\right] 2 \mathrm{~s}$ specimens during tensile testing as longitudinal splitting with visual propagation of longitudinal cracks with audible sound, Fig. 10 (a). For $15^{\circ}, 30^{\circ}$, and $45^{\circ}$ specimens, an inclined crack started at off-axis angle and propagated from one end to the other through the specimen widths accompanied by a noise before specimen failure, Figs. $10(b, c, d)$.

\subsection{In-plane Shear Properties of GFRP Specimens}

In-plane shear properties (strength and modulus) of cross-ply glass/polyester composites with different off-axis angles were determined using Iosipescu and double-notch shear tests.

\subsubsection{Iosipescu shear results}

\section{- In-plane shear strength}

The effect of off-axis angle on the shear strength and modulus of GFRP specimens have been investigated using Iosipescu test. Fig.11 shows load-displacement diagrams of the testing machine in Yosipescu shear tests for cross-ply laminate with $\theta^{\circ}=0^{\circ}, 15^{\circ}, 30^{\circ}$, and $45^{\circ}$ respectively.

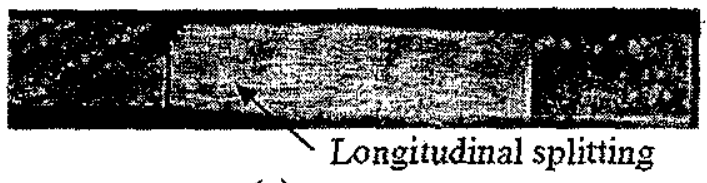
(a)

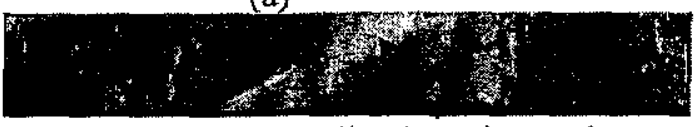

(b)

Inclined crack at $15^{\circ}$

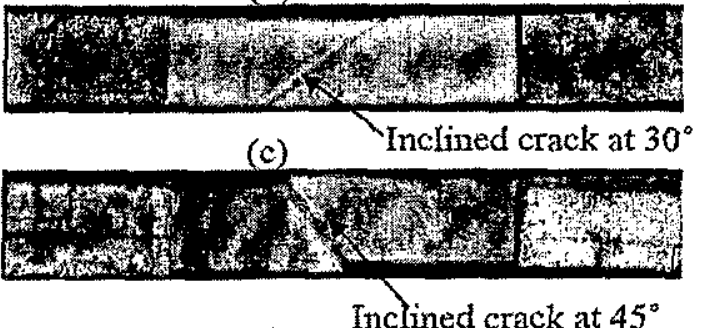

(d)

Inclined crack at $45^{\circ}$

Fig. 10 Failure Modes of $\left[0^{\circ} / 90^{\circ}\right]_{2 s}$ cross-ply laminate with different off-axis angles.

The main characteristic of these curves is the linear behavior in the initial portion. Just beyond proportional limit, it became nonlinear due to the different elastic properties of the constituent materials of the composite laminate that leads to fiber/matrix interface failure. With increasing the applied load the deviation from the linearity increased due to propagation of cracks along the fiber directions and failure of some fibers in the transverse-loading direction. Beyond this point, the friction of pullout fibers and fiber bundles maintained all the applied loads. At this time, visible large cracks were observed between the two notches, Figs. 16 (a)16(d). After the complete failure the load gradually decreased. In this work the in-plane shear strength was calculated based on the maximum load [3] from the following Eq. (2).

$\tau_{x y}=\frac{P_{\max }}{A}$

Fig. 12 shows the effect of off-axis angle on tensile and shear strength. It is obvious that as off-axis angle increases, tensile strength decreases. At $0^{\circ}$ off-axis angle the fiber (in the load direction) resists the load so the material is stronger in this direction so the tensile strength of GFRP, in this direction, is the best. As the off-axis increases the resistance of the 
material decreases so it is easier to fail (fiber is not in the loading direction so the material resistance decreases).

As off-axis angle increases the in-plane shear strength increases, as shown in Fig. 12, this is because at $0^{\circ}$ off-axis angle the fiber can not resist deformation in the direction of maximum shear (at $45^{\circ}$ ) with respect to the applied load. However, such a lay-up would have a relatively low tensile strength.

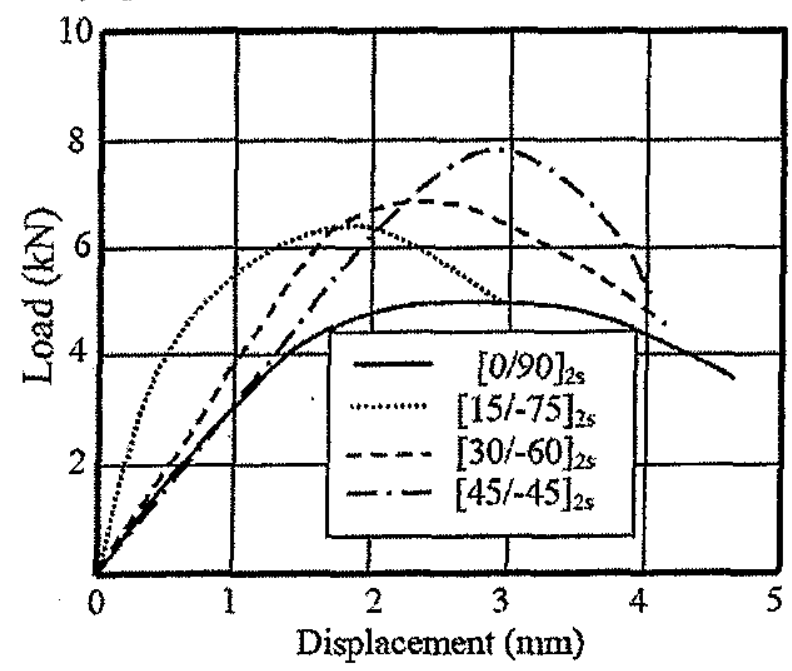

Fig. 11 Load-displacement diagram of cross - ply laminate with $0^{\circ}$ off-axis angle (taken from the testing $\mathrm{m} / \mathrm{c}$ ).

\section{- In-plane shear Modulus}

Fig.13 shows the experimental relationship between the shear stress ( $\tau x y$ ) and strains measured from $+45^{\circ}$ and $-45^{\circ}$ strain gages on the test specimens. The values of shear strain $\left(\gamma_{x y}\right)$, related to shear stresses, were calculated from the results of strains of $+45^{\circ}$ and $-45^{\circ}$ strain gages represented in Fig. 13 using the following equation:-

$$
\left(\gamma_{x y}\right)=\varepsilon_{-45}-\varepsilon_{+45}
$$

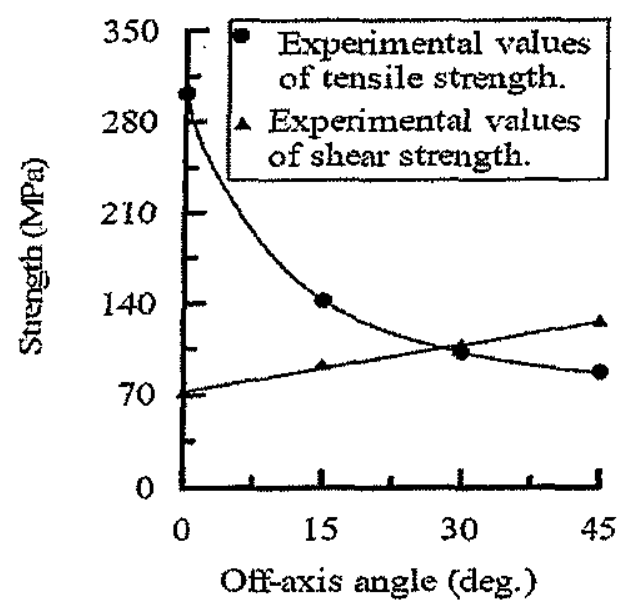

Fig. 12 The relationship between the shear strength and the off-axis angle.

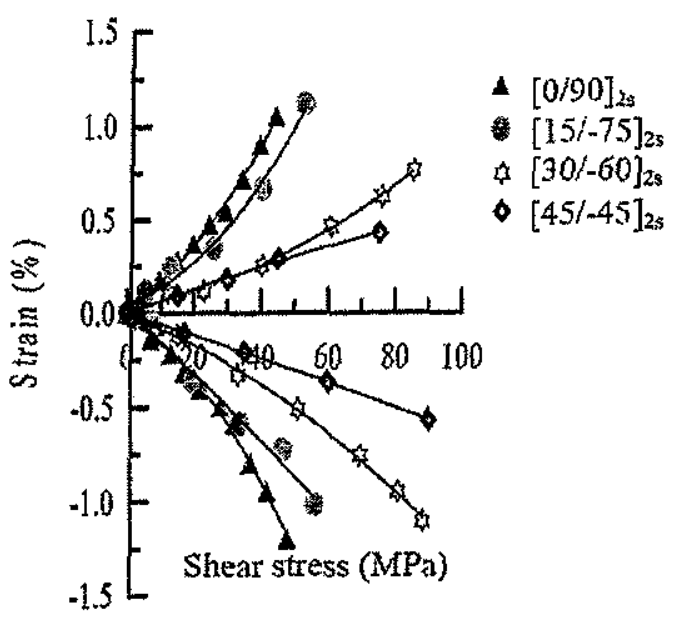

Fig. 13 Stress-strain relationship of cross-ply laminate with different off-axis angle.

Fig. 14 shows the constructed shear stress-shear strain diagrams.

The values of shear modulus have been determined experimentally from the slope of the shear stressstrain curve, represented in Figs. 14, at $0.5 \%$ strain. The values of in-plane shear modulus were calculated from the following equation:-

$$
G_{x y}=\frac{\tau_{x y}}{\gamma_{x y}}
$$

where: $\left(\gamma_{x y}\right)($ shear strain $)=\varepsilon_{.45}-\varepsilon_{+45}$.

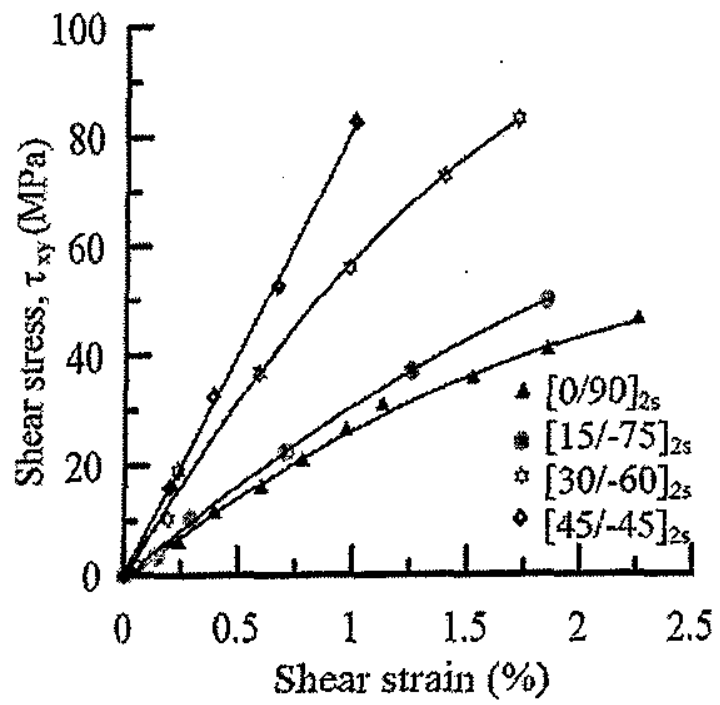

Fig. 14 Shear stress-shear strain relationship of crossply laminate with different off-axis angle.

Fig. 15 and Table 4 show a comparison between the experimental and predicted values of in-plane shear modulus of GFRP specimens with different off-axis angles. 


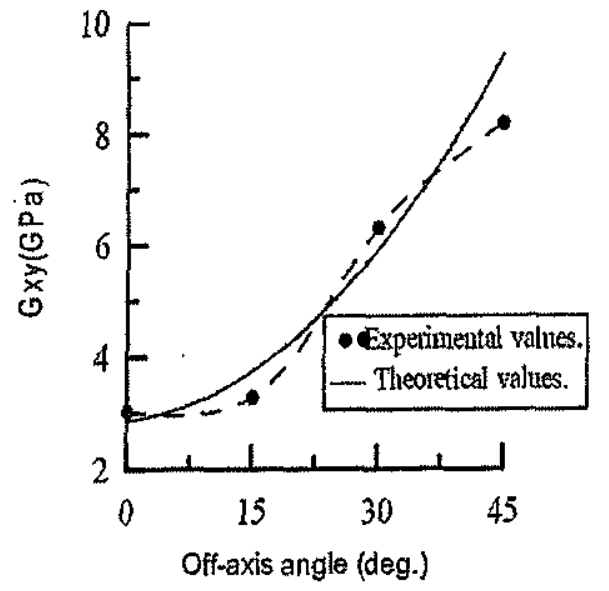

Fig. 15 Relationship between the shear modulus and off-axis angles.

\section{•• Failure Modes}

Specimens with $0^{\circ}$ off-axis angle were failed in Iosipescu test due to pure shear stress along the two $\mathrm{V}$-notches roots. Shear cracks parallel to the loading direction connected the roots of the $V$-notches were observed, Fig. 16 (a).

The cracks in $15^{\circ}, 30^{\circ}$, and $45^{\circ}$ off-axis angle specimens were initiated at the roots of the V-notches and propagated along the fiber directions. With increasing the load more cracks occurred around the notch roots instead of the center region between the notches. By continuously increasing the loading, crushing the materials at the inner loading points was occurred due to stress concentration, Figs. 16 (b)-16 (d).

Table 4: The in-plane shear properties of cross-ply GFR/polyester laminate with different off-axis angles.

\begin{tabular}{|c|c|c|c|c|}
\hline Off-axis angle & $\begin{array}{c}\text { Stacking } \\
\text { sequence }\end{array}$ & Shear strength (MPa) & \multicolumn{2}{|c|}{ In-plane shear modulus (GPa) } \\
\cline { 4 - 5 } & {$\left[0^{\circ} / 90^{\circ}\right]_{2 s}$} & 70.86 & 3.04 & Theoretical \\
\hline $0^{\circ}$ & {$\left[15^{\circ} /-75^{\circ}\right]_{2 s}$} & 90.76 & 3.6 & 3.17 \\
$30^{\circ}$ & {$\left[30^{\circ} / 60^{\circ}\right]_{2 s}$} & 107.36 & 6.3 & 3.97 \\
$45^{\circ}$ & {$\left[45^{\circ}-45^{\circ}\right]_{2 s}$} & 124.74 & 8.16 & 5.88 \\
\hline
\end{tabular}

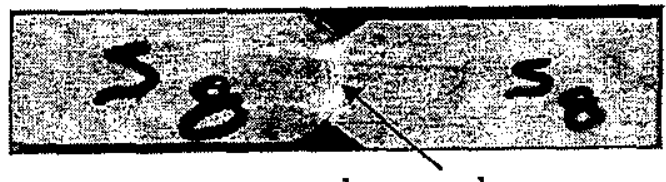

(a)

shear crack

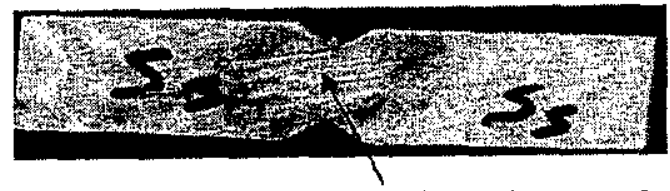

(b)

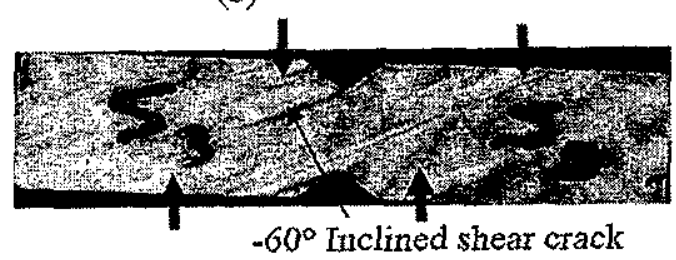

(c)

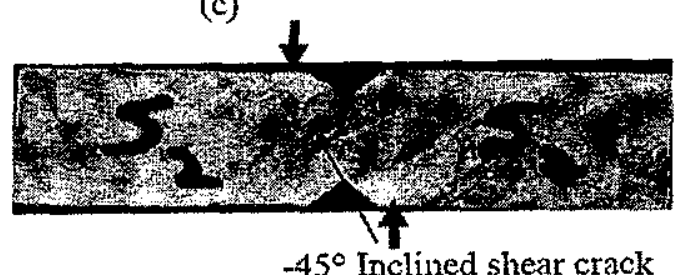

Fig. 16 Iosipescu failed specimens.

\subsubsection{Double-notch shear results}

\section{- In-plane shear strength}

In this section the in-plane shear behavior of GFRP composite specimens using double-notch shear (DNS) test was studied. The effect of off-axis angle $\left(\theta^{\circ}=0^{\circ}, 15^{\circ}, 30^{\circ}\right.$, and $\left.45^{\circ}\right)$, and shear length $(S=4,7$, and $10 \mathrm{~mm}$ ) on the shear strength of GFRP specimens has been investigated. Figs. 17 to 20 show the load-displacement diagrams of the testing machine in (DNS) test.

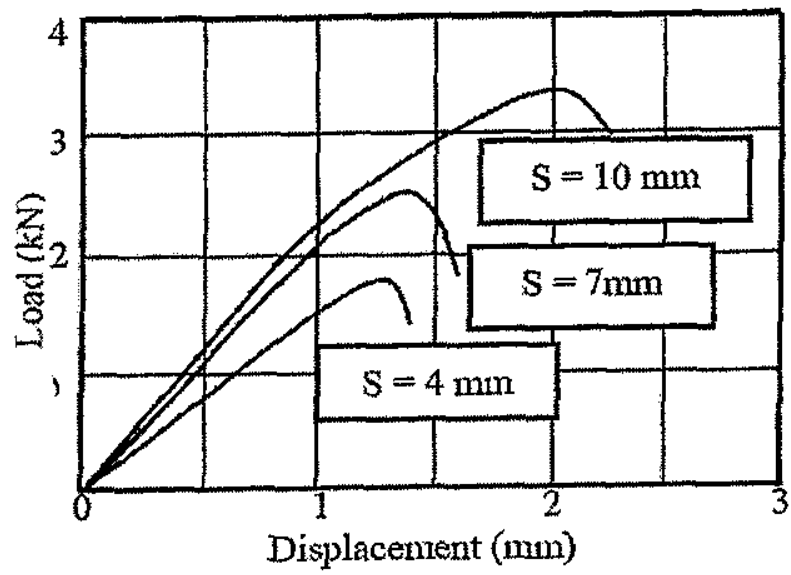

Fig. 17 Load-displacement diagram of cross-ply laminate with various shear lengths using DNS test. 


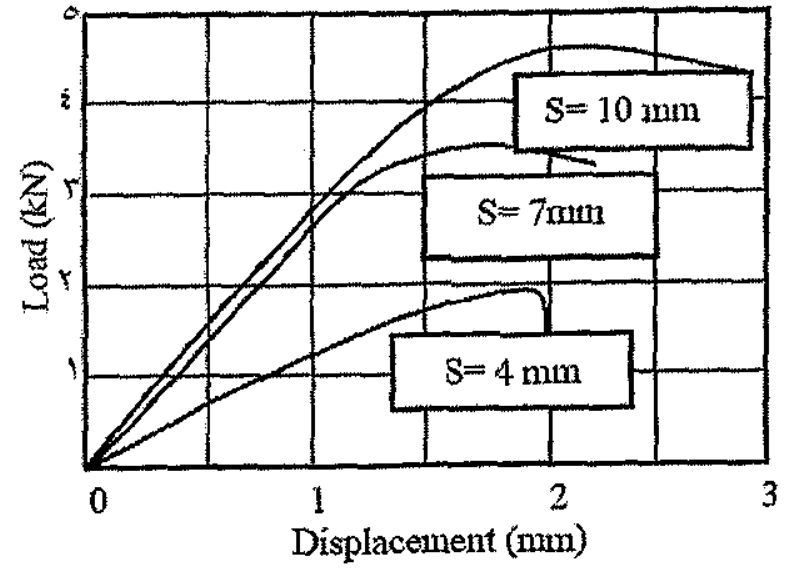

Fig. 18 Load-displacement diagram of $\left[15^{\circ} /-75^{\circ}\right] 2 \mathrm{~s}$ laminate with various shear lengths using DNS test.

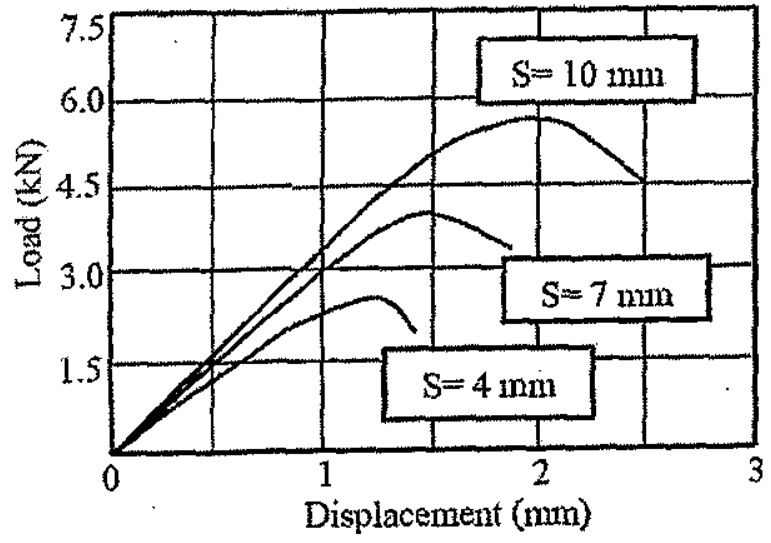

Fig. 19 Load-displacement diagram of $\left[30^{\circ} \% 60^{\circ}\right] 2 \mathrm{~s}$ laminate with various shear lengths using DNS test.

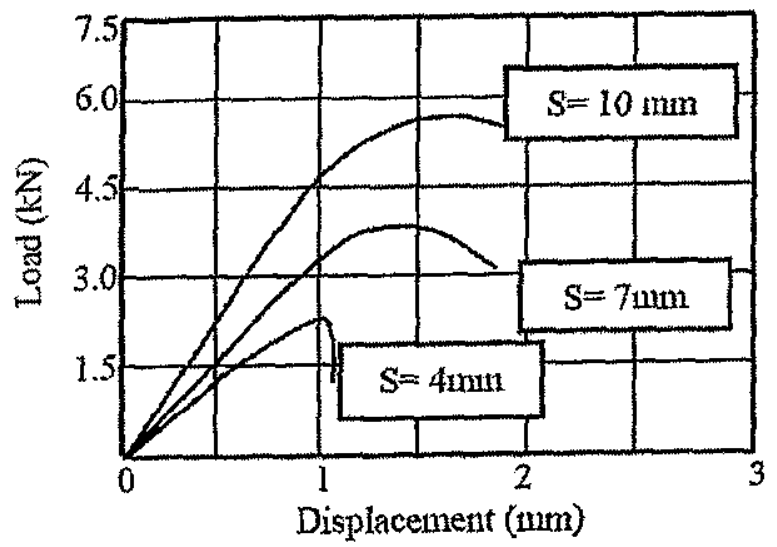

Fig. 20 Load-displacement diagram of $[45 \%-45]_{2 s}$ laminate with various shear lengths using DNS test.

The main characteristic of those curves is the linearity up to a certain point followed by nonlinear portion because of the different elastic properties fiber and matrix. Microcracks develop in matrix then load redistributed between fiber and matrix until fracture occurs.
Fig. 21 shows the relationship between the average shear stress at failure and the shear length (S). The results in these figure indicates that as the shear length (S) increases the value of shear stress decreases. This result is due to the increasing of the bending stress as shear length increases. The value of the maximum in-plane shear strength was obtained by extrapolating the curve $\tau L=f(S)$ to $S=0$. As shear length increases the applied load on the specimen increases so the bending stress increases. To minimize bending stress on the test specimen shear length must be so small (shear length $=0$ ).

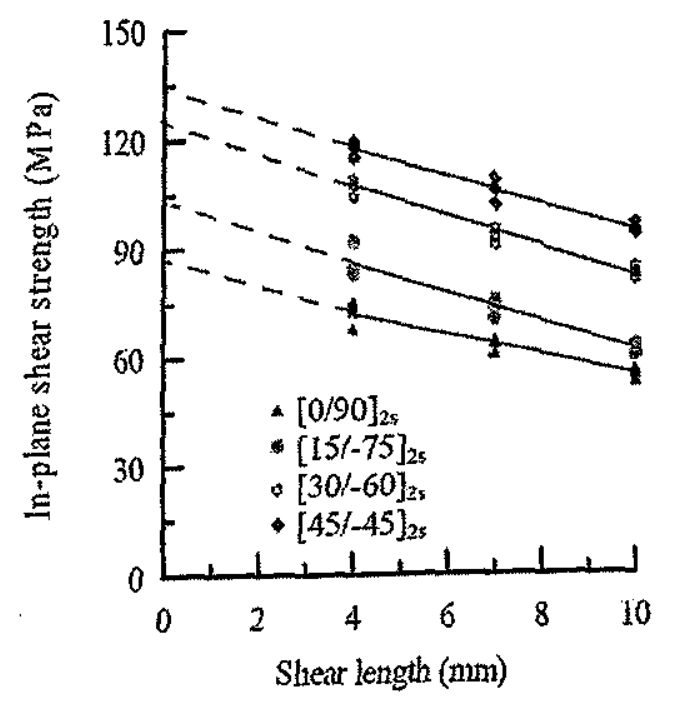

Fig. 21 Relationship between values of shear strength at failure and the shear length(S) for cross-ply DNS specimen.

Fig. 22 indicates a comparison between shear strength of cross-ply laminate with different $\theta^{\circ}$ in Iosipescu and double-notch shear tests. For both tests, the maximum shear strength occurred at off-axis angle $=$ $45^{\circ}$.

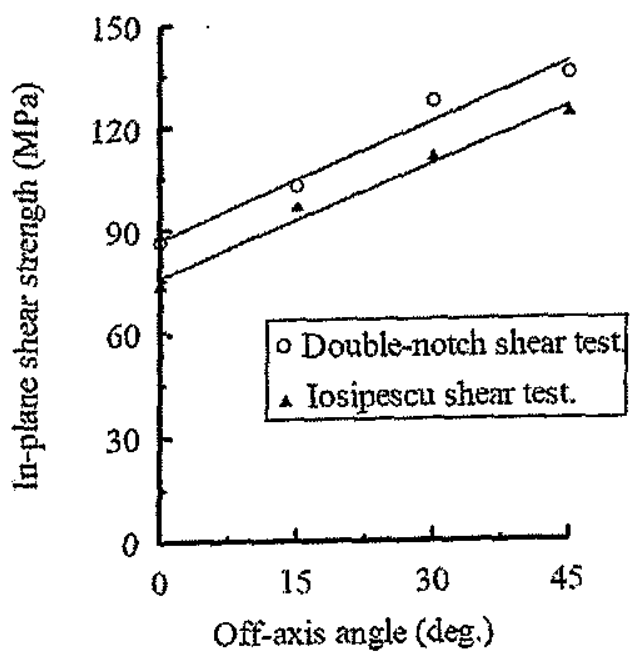

Fig. 22 Relationship between in-plane shear strength and off-axis angles for both Iosipescu and DNS tests 


\section{- Failure modes}

Fig. 23(a) shows a photograph of failed cross-ply specimen in double-notch shear test. Cracks occurred between the two notches along $0^{\circ}$ direction (in the loading direction). Figs. 23(b) to 23(d) show the failure of cross-ply specimen with $15^{\circ}, 30^{\circ}, 45^{\circ}$ offaxis angles respectively. The shear cracks inclined by $15^{\circ}, 30^{\circ}$, and $45^{\circ}$ respectively.

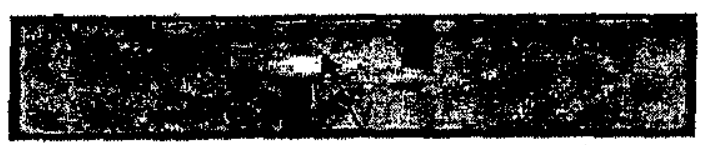

Shear crack along $0^{\circ}$ direction

(a)

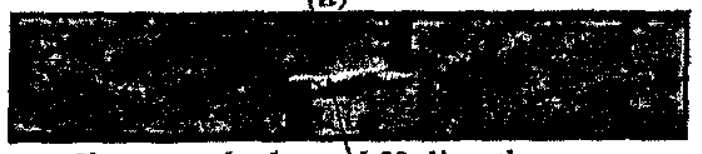

Shear crack along $115^{\circ}$ direction

(b)

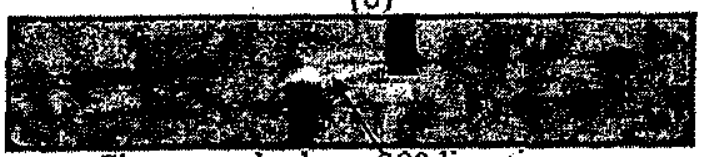

Shear crack along $30^{\circ}$ direction

(c)

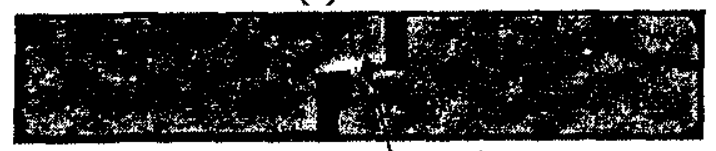

Shear crack along $45^{\circ}$ direction

(d)

Fig. 23 Failed DNS spercimens.

4.1 Prediction of the Elastic Properties of Crossply Composite Laminate with Different Offaxis Angles

4.1.1 Determination of elastic properties of unidirectional lamina

The elastic properties of the constituent materials shown in Table 2 are used to calculate the lamina elastic properties in 1-2 principle principal coordinate system under plane stress using the following equations [12]:

$$
\begin{aligned}
& v_{12}=v_{f} \cdot V_{f}+v_{m} \cdot\left(1-V_{f}\right) \\
& E_{11}=E_{f} \cdot V_{f}+E_{m} \cdot\left(1-V_{f}\right) \\
& E_{22}=E_{m} \times \frac{1+\zeta \eta \eta V_{f}}{1-\zeta \cdot V_{f}}
\end{aligned}
$$

where: $\zeta=2$ for circular fiber.

$G_{12}=G_{m}\left[\frac{\left(1+V_{f}\right) \cdot G_{f}+\left(1-V_{f}\right) G_{m}}{\left(1-V_{f}\right) \cdot G_{f}+\left(1+V_{f}\right) G_{m}}\right]$
4.1.2 Determination of elastic properties of crossply laminate with different off-axis angles.

$E_{x x}=\frac{1}{t A_{11}^{\prime}}, v_{x y}=-\frac{A_{12}^{\prime}}{A_{11}^{\prime}}, G_{x y}=\frac{1}{t A_{66}^{\prime}}$

where:

$A_{i j}^{\prime}$ are the components in the inverse matrix of the lamizate extensional stiffness ,Aij, which calculated as following:

$A_{i j}=\int_{-i / 2}^{t / 2}\left(\bar{Q}_{i j}\right)_{k} d z=\sum_{k=1}^{N}\left(\vec{Q}_{j j}\right)_{k}\left(z_{k}-z_{k-1}\right)$

where:

zk is the ply surface position, $\mathrm{N}$ is the number of plies $(\mathrm{N}=8), \mathrm{t}$ is the whole laminate thickness, $\bar{Q}_{i j}$ is transformed lamina stiffness matrix in $x, y$ coordinate system and can be defined as following [12]:

$$
\begin{aligned}
& \bar{Q}_{21}=Q_{11} \cos ^{4} \theta+Q_{22} \sin ^{4} \theta+2\left(Q_{22}+2 Q_{66}\right) \sin ^{2} \theta \cos ^{2} \theta \\
& \bar{Q}_{12}=\left(Q_{11}+Q_{22}-4 Q_{63}\right) \sin ^{2} \theta \cos ^{2} \theta+Q_{12}\left(\cos ^{4} \theta+\sin ^{4} \theta\right) \\
& \bar{Q}_{22}=Q_{12} \sin ^{4} \theta+Q_{22} \cos ^{4} \theta+2\left(Q_{12}+2 Q_{66}\right) \sin ^{2} \theta \cos ^{2} \theta \\
& \bar{Q}_{60}=\left(Q_{11}+Q_{22}-2 Q_{21}-2 Q_{66}\right) \sin ^{2} \theta \cos ^{2} \theta+Q_{66}\left(\sin ^{4} \theta+\cos ^{4} \theta\right)
\end{aligned}
$$

where $Q_{i j}$ are the components of the lamina stiffness matrix which are related to the engineering constants as:

$$
\begin{aligned}
& Q_{11}=\frac{E_{1}}{1-\nu_{12} \nu_{21}}, Q_{12}=\frac{\nu_{12} E_{2}}{1-\nu_{12} \nu_{21}}=Q_{21}, \\
& Q_{22}=\frac{E_{2}}{1-v_{12} v_{21}}, Q_{66}=G_{12} .
\end{aligned}
$$

\section{CONCLUSIONS}

1. The main characteristic of tensile curves is the knee due to the failure of the transverse layers. redistribution of stress between fibers and matrix was occurred leading to another increasing in the tensile stresses. The final failure is catastrophic without any yielding.

2- The predicted values of the elastic properties (Exx, vxy, Gxy) of cross-ply specimens with different off-axis angles have good agreement with the experimental results.

3- The maximum Poisson's ratio (vxy) is found for specimens with $45^{\circ}$ off-axis angle.

4- The maximum in-plane shear strength is found for specimens with $45^{\circ}$ off-axis angle, $\left[45^{\circ} \%-45^{\circ}\right] 2 \mathrm{~s}$. On the other hand specimens with $0^{\circ}$ off-axis angle have the minimum in-plane shear strength.

5- In Iosipescu shear test, as off-axis angle increases the in-plane shear strength increases. 
6- In Iosipescu shear test, the failure of $\left[0^{\circ} / 90^{\circ}\right] 2 \mathrm{~s}$ specimens was due to pure shear stress along the V-notch roots where shear cracks are parallel to loading direction, while the cracks in $15^{\circ}, 30^{\circ}, 45^{\circ}$ off-axis specimens where initiated at the notch nose and propagated along the fiber directions.

7 - in DNS test, the failure of $\left[0^{\circ} / 90^{\circ}\right] 2 \mathrm{~s}$ specimens was cracks occurred between the two notches along $0^{\circ}$ direction (in the loading direction). In cross-ply specimen with $15^{\circ}, 30^{\circ}$, and $45^{\circ}$ off-axis angles, the shear cracks inclined by $15^{\circ}, 30^{\circ}, 45^{\circ}$. Shear cracks were initiated at U-grooves and rapidly propagated toward the center section of the specimen.

8- In-plane shear strengths determined using DNS test agree with those determined by Iosipescu shear test.

\section{REFERENCES}

[1] Pierron $F$ and Vautrin $A$, "Measurement of the In-plane Shear Strength of Unidirectional Composites With 'The Iosipescu Test", Compos Science \& Tech, Vol.57, pp.1653-1660, (1997).

[2] Han $L$ and Pigott MR, "Tension-Compression and Josipescu Tests on Laminates" Composites Part A, Vol. 33, pp. 35-42, (2002).

[3] Bhatnagar N, Ramakrishnan N, Naik NK and Komanduri R, "On The Machining of Fiber Reinforced Plastic (FRP) Composite Laminates", Int. J. Mach. Tools Manufacture. Vol. 35, No. 5, pp. 701-716, (1995).

[4] Khashaba UA, "In-plane Shear Properties of Cross-ply Composite Laminates with Different off-axis Angles", J Compos Struct, Article in Press, Vol. 10, No. 12, (2003).

[5] Xavier JC, Garrido NM, Oliveira M, Morais JL, Camanho PP and Pierron F, "A Comparison Between The Iosipescu And Off-axis Shear Test Methods For The Characterization of Pinus Pinaster Ait" Composites Part A , Article in Press (2004).

[6] Tarnopol's YM, Arnautov AK, and Kulakov VL, "Methods of Determination of Shear Properties of Textile Composites", Composite Part A, Vol. 30, No. 7, PP. 879-885, (1999).

[7] Davalos JF, Qiao P, Wang J, Salim HA, and Schlussel J, "Shear Moduli of Structural Composites From Torsion Tests", J. Comp. Mat., Vol. 36, No. 10, pp. 1151-1173, (2002).

[8] Unal O, Narottan P, and Bansal, "In-plane and Interlaminar Shear Strength of a Unidirectional Hi-Nicalon Fiber-Reinforced Celsion Matrix Composite", Ceramics Inter, Vol. 28, pp. 527 540, (2002).

[9] ASTM, "Standard Test Method for In-Plane Shear Strength of Reinforced Plastics", Designation D2,346-02, (2002).

[10] ASTM D5379-93, Test Method for "Shear Properties of Composite Materials by the VNotched Beam Method". Philadelphia, PA: American Society for Testing and Materials; 1993.

[11] BS 3691, "E-glass Fiber Roving for Reinforcement of Polyester and Epoxy Resin System", (1990).

[12] Gibson RF, "Principles of Composite Material Mechanics", McGraw-Hill, Inc.; (1994). 